HSV

\title{
The psychosocial impact of serological herpes simplex type 2 testing in an urban HIV clinic
}

\author{
J L Meyer, R A Crosby, W L H Whittington, D Carrell, R Ashley-Morrow, A S Meier, \\ R D Harrington, R DiClemente, A Wald
}

Sex Transm Infect 2005;81:309-315. doi: 10.1136/sti.2004.012146

See end of article for authors' affiliations

.....................

Correspondence to: Anna Wald, MD, MPH, University of Washington Virology Research Clinic, 600 Broadway, suite 400 , Seattle, WA 98122, USA; annawald@u.washington. edu

Accepted for publication 14 October 2004
Background/objectives: Herpes simplex virus type 2 (HSV-2) is a common infection among HIV infected people. HSV type specific serologies permit the diagnosis of previously unrecognised HSV-2 infection. While substantial psychosocial morbidity has been associated with a clinical diagnosis of genital herpes, the burden associated with a serological diagnosis of HSV-2 is unclear. This study prospectively measured the psychosocial response to a new serological HSV-2 diagnosis in patients receiving care at an urban HIV clinic.

Methods: At entry, sera were tested for HSV-1 and HSV-2 antibodies by western blot. Participants completed a 90 item psychosocial and life quality questionnaire at enrolment, and at 2 weeks, 3 months, and 6 months after receiving test results.

Results: Of 248 HIV infected participants, 172 (69.4\%) were HSV-2 seropositive and 116 (67.4\%) seropositive people did not have a previous history of genital herpes. After correction for multiple comparisons, no statistically significant differences were detected on the psychosocial and life quality scales between those who received a new HSV-2 serological diagnosis compared with those who were HSV-2 seropositive with a history of genital herpes, or those who tested HSV-2 seronegative. Additionally, no significant changes in scores were observed during follow up.

Conclusions: HSV-2 was a common but often unrecognised infection in this urban HIV clinic and participants coped well with a positive HSV-2 result. Concerns about psychosocial burden should not deter serological testing for HSV-2. Given the epidemiological and clinical interaction between HSV-2 and HIV, these data support routine HSV-2 testing of HIV infected people.
$\mathrm{H}$ erpes simplex type-2 (HSV-2) is a common infection among HIV infected people and HSV-2 prevalence among HIV infected people often exceeds $50 \%{ }^{1-3}$ The impact of HSV-2 infection on HIV acquisition and transmission, as well as the potential effects of HSV-2 on systemic HIV replication have been described. ${ }^{4-6}$ Any intervention to disrupt the synergy between HIV and HSV-2 is likely to rely on serological identification of HSV-2 infection among HIV infected people. However, no recommendations to routinely identify HIV infected people with HSV-2 infection have been proposed.

Until recently, the diagnosis of genital herpes was based on typical presentation of genital ulcerations, with or without laboratory confirmation by viral culture. However, most people with HSV-2 infection, as well as most who transmit HSV-2, have unrecognised infection. ${ }^{78}$ With the commercial availability of HSV type specific serological tests, those with unrecognised HSV-2 infection may be diagnosed, and such serological tests are likely to be an integral component of a genital herpes prevention programme. ${ }^{9}$ Advocates of routine serological screening for HSV-2 suggest that detection of unrecognised HSV-2 infection may result in behaviour changes that could prevent transmission to partners, and that HSV-2 control through routine condom use and judicious use of suppressive antiviral therapy may be important means of limiting HSV-2 transmission. ${ }^{10}{ }^{11}$ Conversely, opponents of screening believe that identifying those with mild or asymptomatic HSV-2 infection may result in the significant psychosocial sequelae associated with a clinical genital herpes diagnosis, outweighing the potential benefits of detection. ${ }^{12-14}$

Among STD clinic attendees, adverse psychosocial outcomes associated with a serological diagnosis of genital herpes were modest. ${ }^{15}{ }^{16}$ In a recent qualitative study of 24 individuals, a new serological HSV-2 diagnosis was associated with strong psychosocial responses. However, this research suggested that the observed negative feelings could be amenable to counselling or the passage of time. ${ }^{17}$ The present study was designed to prospectively measure the psychosocial response associated with a serological HSV-2 diagnosis among patients presenting to an urban, hospital based HIV clinic. Similar to a clinical diagnosis of genital herpes, we expected a measurable amount of stress to be associated with an initial serological HSV-2 diagnosis. However, we hypothesised that the psychosocial stress in an individual would subsequently decrease over the course of this 6 month study.

\section{METHODS}

\section{Participants and setting}

This study was conducted at an urban HIV clinic located in a county hospital in Seattle, WA, that provides primary care and social services for HIV infected adults. Between October 2001 and April 2002, 248 HIV infected patients were recruited when they presented for regularly scheduled visits. Eligible people were English speaking, between the ages of 18-55, and had not had a negative HSV-2 serological test in the past year.

After written informed consent, data collection consisted of self administered questionnaires that assessed demographic

Abbreviations: GEE, generalised estimating equations; $H B M$, Health Belief Model; HRQoL, Herpes Related Quality of Life; HSV-2, herpes simplex type 2; MSSCQ, Multidimensional Sexual Self Concept Questionnaire; POMS, Profile of Mood States 
Table 1 Sample items from the quality of life and psychosocial questionnaire

Herpes related quality of life
I worry that sex will trigger an outbreak of herpes
$\square$ Yes, very difficult
It is difficult to forget that I have herpes.
$\square$ Yes, very difficult
Present sexual satisfaction
I feel that my partner enjoys our sex life
$I$ Yes, quite difficult
None of the time
Multidimensional sexual self concept, sexual optimism subscale
I will likely experience some sexual problems in the future $\quad \square$ Yes, a little difficult
$\square$ Yes, very likely
$\square$ Not at all likely
Ways of coping
In dealing with problems in the past 3 months have you...
Tried to keep your feelings to yourself?
$\square$ Not at all

characteristics, medical and sexual histories, and a 90 item psychosocial and life quality scale. Participants were provided with HSV-2 test results by phone approximately 2 weeks after enrolment. Those patients who tested HSV-2 seropositive were provided with information about genital herpes and counselled about the natural history of infection and risk of transmission to partners. The psychosocial questionnaires and interim sexual histories were again completed at 2 weeks, 3 months, and 6 months after test results were given. The University of Washington institutional review board approved the study protocol.

\section{Quality of life and psychosocial scales}

Self administered questionnaires were used to measure the emotional, social/occupational, and relationship burdens associated with a new HSV-2 serological diagnosis (see table 1 for examples). Internal reliability, assessed using Cronbach's alpha, was calculated from the baseline life quality questionnaire before scoring of the individual psychosocial subscales. Since each item is correlated with the construct of the scale, person level mean substitution was used to estimate missing responses $(<10 \%$ of the data were so estimated). Scales with more than one missing value were excluded (with exception to the Profile of Mood States and Herpes Related Quality of Life, for which two missing values were allowed).

\section{Profile of Mood States}

Psychological distress was measured through the Profile of Mood States Brief (POMS) questionnaire that contained 30 items from the original 65 item scale. ${ }^{18}$ Participants were asked how they had been feeling during the past week and each characteristic-for example, tense, sad, or lonely, was rated on a 5 point scale ranging from 0 (not at all) to 4 (extremely). The mood scales included tension-anxiety, depression-dejection, anger-hostility, vigour-activity, fatigue-inertia, and confusion-bewilderment. A composite score, total mood disturbance, was calculated by summing each of the individual scores for tension, depression, anxiety, fatigue, and confusion, with vigour scores subtracted. ${ }^{19}$ Cronbach's alpha was 0.86 for tension-anxiety, 0.88 for depressiondejection, 0.86 for anger-hostility, 0.87 for vigour-activity, 0.90 for fatigue-inertia, and 0.70 for confusion-bewilderment.

\section{Herpes Related Quality of Life (HRQoL)}

Among HSV-2 seropositive participants, the impact of genital herpes on health related quality of life was measured by 25 herpes specific questions, scored on a 4 point scale as previously described. ${ }^{20}$ The HRQoL was only administered to HSV-2 seropositive participants during post-test visits. A higher score indicated greater quality of life. Cronbach's alpha for this scale at the 2 week visit was 0.92

Sexual relationships: present and future satisfaction Twelve questions pertaining to current sexual satisfaction were included and participants utilised a 7 point scale. A total score was calculated; a higher score indicated decreased current sexual satisfaction. Cronbach's alpha for present sexual satisfaction at the 2 week visit was 0.83 .

The sexual optimism scale of the Multidimensional Sexual Self Concept Questionnaire (MSSCQ) was utilised to measure anticipated future sexual satisfaction. ${ }^{21}$ Sexual optimism is defined as the expectation that the future sexual aspects of one's life will be positive and rewarding. The values of individual responses (range of $0-4$ ) were averaged and a higher score suggested greater optimism.

\section{Ways of coping}

Six scales, derived from the ways of coping, ${ }^{22}$ including distancing, self controlling, seeking social support, and escape avoidance, were assessed. Participants were asked to respond to each item on a 4 point scale, to indicate the frequency with which each strategy was used $(0=$ not at all, $3=$ most of the time) in the 3 months before the study visit. Results are presented as the mean response for each item and higher values indicate a greater tendency to use that coping strategy. Since six different scales were to assess ways of coping, the significance level for these comparisons was revised with a Bonferroni correction. The significance level was considered $\alpha / 6=0.0083$.

\section{Health Belief Model-perceived severity subscale}

The Health Belief Model (HBM) seeks to identify cognitive factors predisposing people to voluntarily engage in preventive health behaviours or seek services for morbid conditions. ${ }^{23}$ The perceived severity component of the HBM defines the individual's assessment of consequences of contracting a disease/condition or leaving the condition untreated. Perceived severity is an important psychological construct that underlies several theories in health behaviour and is postulated to be a primary determinant of how people view and respond to any given health threat. ${ }^{24-26}$ The level of perceived severity may be an important determinant of the magnitude of the action. ${ }^{27}$

Participants were asked to rate 13 situations that may be considered stressful on a 5 point scale $(1=$ not at all traumatic, $5=$ extremely traumatic), including involvement in a car accident, the death of a close friend, or a chronic disease diagnosis as well as genital herpes. The results are 
Table 2 Demographic, behavioural, and clinical characteristics of study population

\begin{tabular}{|c|c|c|c|}
\hline & \multirow{2}{*}{$\begin{array}{l}\text { HSV-2 negative } \\
\text { No }(\%)\end{array}$} & \multirow{2}{*}{$\begin{array}{l}\text { HSV-2 positive, } \\
\text { previous history } \\
\text { No }(\%)\end{array}$} & \multirow{2}{*}{$\begin{array}{l}\text { HSV-2 positive, no } \\
\text { previous history } \\
\text { No (\%) }\end{array}$} \\
\hline & & & \\
\hline Age, median (range) & $38(23-53)$ & $40(22-56)$ & $41(26-55)$ \\
\hline Sex, men & $70(92.1)$ & $42(75.0)$ & $99(85.3)$ \\
\hline \multicolumn{4}{|l|}{ Education } \\
\hline College graduate & $4(5.3)$ & $7(12.5)$ & $20(17.2)$ \\
\hline High school graduate/some college & $60(80.0)$ & $39(69.6)$ & 81 (69.8) \\
\hline Not high school graduate & 11 (14.7) & 10 (17.9) & 15 (12.9) \\
\hline \multicolumn{4}{|l|}{ Race } \\
\hline White & $61(80.3)$ & $36(64.3)$ & $69(59.5)$ \\
\hline African-American & $5(6.6)$ & $7(12.5)$ & $31(26.7)$ \\
\hline Other & 10 (13.2) & $13(23.2)$ & $16(13.8)$ \\
\hline \multicolumn{4}{|l|}{ Insurance status } \\
\hline Private & $16(22.9)$ & 10 (18.2) & $14(12.8)$ \\
\hline Public & $45(64.3)$ & $41(74.5)$ & 77 (70.6) \\
\hline None & $9(12.9)$ & $4(7.3)$ & $18(16.5)$ \\
\hline \multicolumn{4}{|l|}{ Marital status } \\
\hline Married/living together & $17(22.4)$ & $16(29.1)$ & $36(31.6)$ \\
\hline Previously married & $20(26.3)$ & $16(29.1)$ & $30(26.3)$ \\
\hline Never married & $39(51.3)$ & $23(41.8)$ & $48(42.1)$ \\
\hline \multicolumn{4}{|l|}{ Household income } \\
\hline$\$ 30001+$ & $12(16.2)$ & $7(12.5)$ & $9(8.1)$ \\
\hline$\$ 15000-\$ 30000$ & $17(23.0)$ & $10(17.9)$ & $25(22.5)$ \\
\hline less than $\$ 15000$ & $45(60.8)$ & 39 (69.6) & $77(69.4)$ \\
\hline AIDS diagnosis* & $35(46.0)$ & 35 (62.5) & $60(62.5)$ \\
\hline \multicolumn{4}{|l|}{ Sex partners in past 2 months } \\
\hline 0 & $32(42.1)$ & $22(39.3)$ & $42(36.2)$ \\
\hline 1 & $23(30.3)$ & $19(33.9)$ & $48(41.4)$ \\
\hline$\geqslant 2$ & $21(27.6)$ & $15(26.8)$ & $26(22.4)$ \\
\hline History of other STD & $53(69.7)$ & $52(92.9)$ & $90(77.6)$ \\
\hline Known previous partner with HSV-2 & $17(22.4)$ & $21(37.5)$ & 19 (16.4) \\
\hline \multicolumn{4}{|l|}{ HSV serology results } \\
\hline HSV-1 positive & $65(85.5)$ & - & - \\
\hline HSV-2 positive & - & $24(42.9)$ & $47(40.5)$ \\
\hline HSV- 1 and HSV- 2 positive & - & $32(57.1)$ & $69(59.5)$ \\
\hline HSV seronegative & $11(14.5)$ & - & - \\
\hline
\end{tabular}

reported as the mean response of all participants to each item.

\section{Laboratory methods}

At enrolment, sera were tested for HSV-1 and HSV-2 antibodies by western blot. ${ }^{28}$

\section{Statistical analysis \\ Sample size}

We hypothesised that participants with a new serological diagnosis of HSV-2 will initially experience psychosocial distress, but that adjustment will occur within 6 months. To calculate the sample size, estimated mean differences and variances were obtained from a study by Patel et al, which measured the increase in quality of life associated with suppressive antiviral therapy. ${ }^{29}$ These investigators scored the HRQoL on a scale of 0 to 60 , whereas ours was scored on a 100 point scale. Therefore, the mean difference and variances used for the calculations were scaled accordingly. Assuming $\alpha=0.05$ and $\beta=0.10$, it was estimated that 77 participants with a new serological diagnosis of HSV-2 must be followed to detect a difference of 5 and 26 to detect a difference of 10 on the HRQoL.

\section{Psychosocial scales}

Current literature suggests the psychosocial repercussions of a new serological HSV-2 diagnosis may be transitory. ${ }^{17}$ Therefore, statistical tests were chosen to detect early changes in summary scores which may resolve. Each psychosocial scale was analysed separately using generalised estimating equations (GEE) with an identity link (for normally distributed outcomes). These models account for the correla- tion of measures taken on the same subject and are appropriate when assessing measures that are assessed repeatedly over time. Differences in scores over time and between participants with different HSV-2 history/status were assessed simultaneously using GEE. HSV-2 history/ status was summarised in three categories: "HSV-2 negative," "HSV-2 positive, no previous history," and "HSV-2 positive, previous history." In scores where a baseline measure was obtained before HSV-2 testing, both linear and quadratic time effects were examined. Where only postnotification measures were obtained ( 2 weeks, 3 months, and 6 months) only linear time effects were assessed. Sex and race were also entered into secondary models. No interactions with gender or race could be considered, since most participants were male and white. The only interaction terms examined were those of HSV-2 history/status and time, where time could be expressed linearly (numerically) and quadratically (squared).

GEE models were performed on summary scores within each scale, with the intention of performing additional, separate modelling of subscales should overall significance be found. Since the different "ways of coping" had no appropriate summary measure, each of these was examined separately.

\section{RESULTS}

The median age of the 248 participants was 40 years (range 22-66); 211 (85.1\%) were male and 166 (66.9\%) were white (table 2). An annual household income of less than \$15000 was reported by 161 (64.9\%) and $173(69.7 \%)$ had publicly funded health care. Overall, 145 (62.2\%) had had an AIDS diagnosis. Characteristics of the study population were 
Table 3 Profile of Mood States, by HSV-2 serostatus and study visit

\begin{tabular}{|c|c|c|c|c|}
\hline & \multicolumn{4}{|c|}{ Mean score $(\mathrm{SD})^{\star} \dagger$} \\
\hline & Baseline & 2 weeks & 3 months & 6 months \\
\hline \multicolumn{5}{|c|}{ HSV-2 positive, no previous history } \\
\hline Anger-hostility & $6.1(4.9)$ & $5.7(5.0)$ & $6.2(5.1)$ & $5.7(5.3)$ \\
\hline Fatigue-inertia & $8.4(5.3)$ & $7.6(5.5)$ & $8.8(5.4)$ & $8.1(5.7)$ \\
\hline Vigour-activity & $8.4(4.4)$ & $8.3(4.9)$ & $7.5(5.3)$ & $8.0(4.4)$ \\
\hline Depression-dejection & $6.4(5.4)$ & $6.2(5.5)$ & $6.4(5.5)$ & $6.2(5.6)$ \\
\hline Confusion-bewilderment & $6.6(4.0)$ & $6.5(4.3)$ & $6.9(3.9)$ & $6.6(4.1)$ \\
\hline Tension-anxiety & $6.8(5.1)$ & $6.2(4.9)$ & $6.6(4.7)$ & $6.0(5.0)$ \\
\hline Mood disturbance & $26.0(22.9)$ & $24.0(24.0)$ & $27.3(23.3)$ & $24.3(24.6)$ \\
\hline \multicolumn{5}{|c|}{ HSV-2 positive, previous history } \\
\hline Anger-hostility & $6.0(4.5)$ & $5.8(4.9)$ & $5.7(5.0)$ & $5.7(4.4)$ \\
\hline Fatigue-inertia & $9.7(4.9)$ & $8.7(5.0)$ & $8.8(5.1)$ & $8.5(5.0)$ \\
\hline Vigour-activity & $7.1(4.4)$ & $8.2(5.1)$ & $8.1(4.9)$ & $7.2(4.5)$ \\
\hline Depression-dejection & $6.8(5.7)$ & $6.2(5.1)$ & $6.0(5.0)$ & $5.6(4.2)$ \\
\hline Confusion-bewilderment & $7.4(4.1)$ & $7.1(4.2)$ & $6.7(3.9)$ & $6.3(3.5)$ \\
\hline Tension-anxiety & $7.2(5.4)$ & $6.4(5.0)$ & $7.0(5.2)$ & $6.9(5.1)$ \\
\hline Mood disturbance & $30.3(21.0)$ & $26.1(21.5)$ & $26.2(23.2)$ & $24.9(18.0)$ \\
\hline \multicolumn{5}{|l|}{ HSV-2 negative } \\
\hline Anger-hostility & $5.4(4.2)$ & $5.5(4.4)$ & $6.0(4.6)$ & $5.6(3.8)$ \\
\hline Fatigue-inertia & $8.2(5.3)$ & $8.6(5.5)$ & $92(5.3)$ & $8.4(4.7)$ \\
\hline Vigour-activity & $8.5(4.6)$ & $8.3(4.9)$ & $7.6(4.7)$ & $7.9(4.4)$ \\
\hline Depression-dejection & $5.2(4.7)$ & $5.5(4.9)$ & $5.7(4.9)$ & $5.3(4.0)$ \\
\hline Confusion-bewilderment & $5.8(3.6)$ & $6.1(4.2)$ & $7.0(3.7)$ & $6.6(4.1)$ \\
\hline Tension-anxiety & $6.4(4.5)$ & $7.0(5.1)$ & $6.8(4.5)$ & $6.7(4.3)$ \\
\hline Mood disturbance & $22.6(22.0)$ & $24.7(24.2)$ & $26.5(21.2)$ & $24.5(19.2)$ \\
\hline
\end{tabular}

similar to all 1,163 people attending the HIV clinic, where $61.7 \%$ were white, $80.6 \%$ were male, $49 \%$ had public insurance, and $62.9 \%$ had had an AIDS diagnosis.

Among the 248 participants, 172 (69.4\%) were HSV-2 seropositive. Of those who were HSV-2 seropositive, only 56 $(32.6 \%)$ reported a history of genital herpes. Three additional participants with HSV-l infection only reported a history of genital herpes.

Regardless of history of genital herpes, HSV-2 seropositive people were more likely to be female, to be other than white, and more likely to have a history of another STI $(\mathrm{p}<0.05$, each comparison, table 2). At enrolment, 152 (61.3\%) of all study participants were currently sexually active, $62(25.0 \%)$ reported more than one partner in the 2 months before enrolment, and level of sexual activity did not differ by HSV-2 serostatus or history of genital herpes $(p=0.67)$. Participant retention remained high throughout the study; 236 (95.2\%) returned at 2 weeks, $227(91.5 \%)$ returned at 3 months, and $226(91.1 \%)$ of 248 returned at 6 months.

\section{Psychosocial scale outcomes}

\section{Profile of mood states}

The total mood disturbance score was not found to be associated with time (linear, $p=0.29$; quadratic, $p=0.25$ ) or with HSV-2 history/status when comparing those with a history of HSV-2 with either those with a new diagnosis or those seronegative for HSV-2 ( $p=0.47$ and $p=0.72$, respectively) (table 3 ). No statistically significant associations were found for total mood disturbance with either sex or race. Since no associations were found to correspond to the total mood score, subscales (anger, fatigue, confusion, depression, tension, and vigour) were not examined individually.

\section{Herpes Related Quality of Life (HRQoL)}

Only subjects positive for HSV-2 completed the Herpes Related Quality of Life surveys. Scores were not found to differ over time $(p=0.63)$ or by history of HSV-2 positivity $(p=0.28)$. No interaction terms were found to demonstrate statistical significance. In secondary analysis, African American participants rated their summary quality of life score, on average, 7 points below white people and others $(p=0.0087)$, independent of time and history of HSV-2.

Sexual relationships: present and future satisfaction Sexual satisfaction was not found to differ over the course of follow up (for linear trend, $\mathrm{p}=0.76$; for quadratic trend, $\mathrm{p}=0.84$ ) or when comparing participants with previous history of HSV-2 with either newly diagnosed subjects $(p=0.40)$ or HSV-2 negative participants $(p=0.97)$. No interaction was found with time and HSV-2 history/status. Sex and race trends were not found to be statistically significant $(\mathrm{p}=0.90$ and $\mathrm{p}=0.19$, respectively).

The MSSCQ was also completed only by participants positive for HSV-2. No statistically significant differences were found over time $(p=0.10)$ or by history of HSV-2 positivity $(p=0.49)$, and no interactions were detected. Neither gender $(p=0.32)$ nor race $(p=0.92)$ were significantly associated with this summary score.

\section{Ways of coping}

Seeking social support as a way of coping decreased over follow up for subjects with a new diagnosis of HSV-2 $(p=0.018$ for linear trend), but was not found to change for other subgroups. Among subjects with a new diagnosis of HSV-2, the mean score decreased from 1.4 at baseline to 1.0 at the 6 month visit. The significance level reported is that of the interaction term of HSV-2 newly diagnosed with time (linear) relative to HSV negative subjects. Use of alcohol was found to initially decrease, then increase (convex shape) slightly over follow up, $(\mathrm{p}=0.019$ and 0.018 for linear and quadratic time trends, respectively). This effect was found to be independent of HSV-2 antibody or history. In addition, the change is so small $( \pm 0.1)$ as to not be clinically meaningful. Lastly, using sex to cope was slightly lower at all time points both for those with a new HSV diagnosis (0.12 lower, $\mathrm{p}=0.049)$ and those with a history of HSV-2 (0.14 lower, $\mathrm{p}=0.043$ ) relative to HSV negative subjects. The differences, however, were small, and after adjusting for multiple comparisons, none of the trends observed in ways of coping 
Table 4 Life quality subscale scores by visit and HSV-2 serostatus (mean (SD))

\begin{tabular}{|c|c|c|c|c|}
\hline & Baseline & 2 weeks & 3 months & 6 months \\
\hline \multicolumn{5}{|l|}{ Herpes Related Quality of Life* } \\
\hline HSV-2 positive, previous history & - & 73.7 (12.4) & $73.8(12.6)$ & $75.4(10.8)$ \\
\hline HSV-2 positive, no previous history & - & $76.4(14.0)$ & $75.0(15.7)$ & $76.8(14.4)$ \\
\hline \multicolumn{5}{|l|}{ Present sexual satisfaction $†$} \\
\hline HSV-2 negative & $33.9(12.4)$ & $34.7(12.1)$ & $33.8(10.7)$ & 34.1 (11.9) \\
\hline HSV-2 positive, previous history & $33.7(11.7)$ & $32.1(10.4)$ & $34.6(10.9)$ & $35.7(14.1)$ \\
\hline HSV-2 positive, no previous history & $32.0(13.2)$ & $31.3(11.9)$ & $32.8(13.5)$ & 33.0 (12.7) \\
\hline \multicolumn{5}{|l|}{ Multidimensional sexual self concept‡ } \\
\hline HSV-2 positive, previous history & - & $3.4(0.9)$ & $3.2(0.8)$ & $3.3(0.9)$ \\
\hline HSV-2 positive, no previous history & - & $3.3(0.9)$ & $3.2(1.0)$ & $3.1(0.9)$ \\
\hline \multicolumn{5}{|l|}{ Ways of copings } \\
\hline Distancing & $1.2(1.0)$ & $1.1(1.0)$ & $1.1(1.0)$ & $1.1(1.0)$ \\
\hline Self controlling & $1.6(1.0)$ & $1.4(0.9)$ & $1.5(0.9)$ & $(1.0)$ \\
\hline Seeking social support & $1.5(1.0)$ & $1.3(1.0)$ & $1.2(1.0)$ & $1.2(1.0)$ \\
\hline Escape-avoidance (using alcohol) & $0.7(0.9)$ & $0.6(0.9)$ & $0.6(0.9)$ & $0.7(0.9)$ \\
\hline Escape-avoidance (wishing situation would disappear) & $1.7(1.0)$ & $1.6(1.0)$ & $1.6(1.0)$ & (1.0) \\
\hline Using sex to cope & $0.3(0.6)$ & $0.2(0.5)$ & $0.2(0.5)$ & $0.3(0.6)$ \\
\hline
\end{tabular}

scores were significant (Bonferroni corrected $\alpha$ for six subscales $=0.0083)($ table 4$)$.

Health belief model, perceived severity subscale Trauma associated with receiving a new HSV-2 diagnosis (mean 2.9) in this population was similar to that associated with involvement in a car accident without hospitalisation (mean 2.7), receiving a poor work evaluation (mean 2.8) or finding out that you have high blood pressure (mean 2.9) (fig 1). The loss of a job (mean 3.2), a HIV/AIDS (mean 3.6), prostate/breast cancer (mean 3.6), or diabetes diagnosis (mean 3.6), being robbed (mean 3.7), ending a relationship (mean 3.9), and the death of a close friend (mean 4.2) were ranked as more traumatic than a new herpes diagnosis. Items ranked as less traumatic included moving to a new house or apartment (mean 2.2), or committing a minor violation of the law (mean 2.5). The overall rank of these items did not vary by sex, race, or HSV-2 status (data not shown).

\section{DISCUSSION}

Our prospective study found no evidence of psychosocial morbidity associated with a new serological diagnosis of HSV-2 in HIV infected participants. Among the scales used to measure the emotional, social, and relationship burden associated with HSV-2, no differences were detected between those who received a new HSV-2 serological diagnosis, those

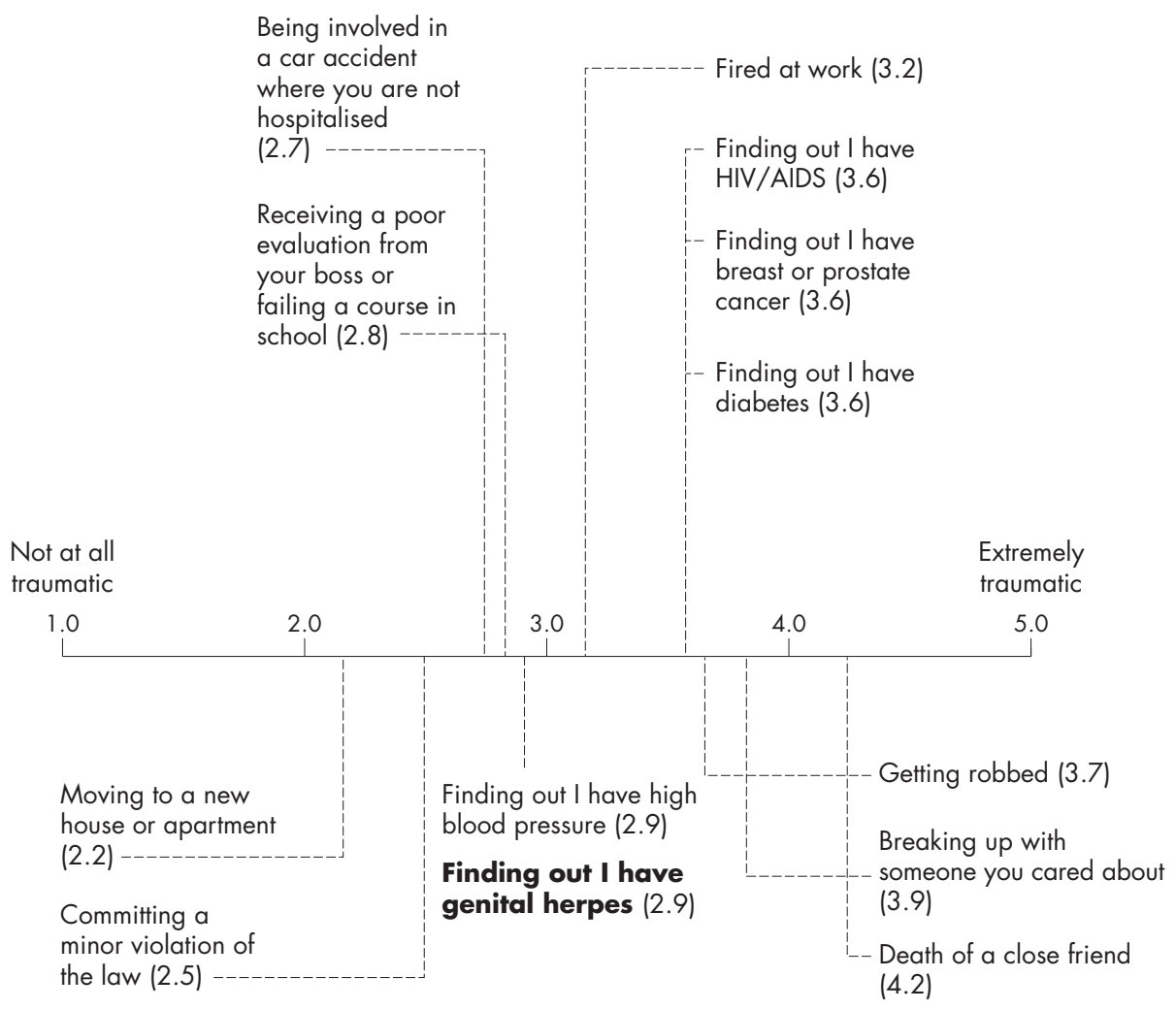

Figure 1 Health Belief Model, perceived severity subscale. Mean response of study subjects at baseline visit. Acquiring genital herpes ranked as only somewhat traumatic, relative to other events that may be perceived as stressful. 
who tested HSV-2 seropositive but had a history of genital herpes, and those who tested HSV-2 seronegative. One of the scales showed a decrease in social support seeking behaviour among those with new diagnosis, but it did not reach statistical significance after correction for multiple comparisons. Additionally, no significant changes were observed over the course of the 6 month follow up period. In relation to other events that may be perceived as stressful, a new genital herpes diagnosis was ranked as only somewhat traumatic. While different scales were used, these findings are in general agreement with the other studies addressing the psychosocial sequelae associated with a new HSV-2 serological diagnosis in people attending an STD clinic $^{15} 30$ and in a qualitative study in people attending a variety of healthcare facilities. ${ }^{17}$

Lack of statistically significant results raises the issue of adequate power. A priori, we calculated that 77 people with a new HSV-2 serological diagnosis were needed to detect a paired difference of 5 points on the HRQoL scale with $90 \%$ power; we enrolled 116. Differences found between groups based on HSV-2 serology and history of genital herpes never exceeded 3 points, a figure that appears not to be clinically relevant. Similarly, the observed effect size was small on other scales, lending support to the conclusion that there is no true difference between the groups and no differences were noted in longitudinal follow up.

The results of this study are striking when compared with the published literature documenting the psychological distress experienced by those with a new clinical diagnosis of genital herpes. ${ }^{12}$ The discrepancy may be partially explained by the frequency and severity of symptoms experienced by those with a clinical versus serological diagnosis of genital herpes. A clinical diagnosis of genital herpes is predicated upon a first episode of genital lesions, which may be a severe illness in a young, otherwise healthy person. Most participants with symptomatic HSV-2 adjust to the diagnosis, although recurrences have been shown to impair this process. ${ }^{13} 29$ In contrast, prevalent cases of HSV-2 infection first detected by serological tests are more likely to be characterised by milder disease. Before testing, these participants were not bothered by genital herpes symptoms, and had little reason to anticipate that they will be in the future. These findings highlight the role of severe clinical illness in determining the subsequent psychosocial function among person with HSV-2 infection.

Another potential explanation of our null results may be linked to the clinical context and social milieu in which this study was performed. Living with HIV infection is inherently stressful, in addition to the poverty, illicit drug use, and mental illness that are often pervasive within this group. As such, it is possible that the scales utilised were not able to detect anxiety attributable to an HSV-2 diagnosis beyond the appreciable level of stress that is already experienced by members of this cohort. Future studies may explore this issue by examining the impact of a serological diagnosis of genital herpes on otherwise healthy people.

Because our observations were made in the context of a research protocol, the consent process and the counselling attendant to the HSV testing were probably more informative than occurs in the course of routine clinical care. This may also have diminished the observed effect of serological testing and allayed anxiety about a positive HSV-2 result to some extent.

Our data recapitulate that HSV-2 is an extremely prevalent and mostly unrecognised infection among HIV seropositive people. The majority $(69.4 \%)$ of this cohort had antibodies to HSV-2, and two thirds of these were not aware of their infection before study entry. Given the high prevalence in this group, even a modest fraction of people experiencing
Key messages

- The majority of HIV infected people have HSV-2 infection

- Testing HSV-2 seropositive does not result in psychosocial morbidity among HIV infected patients

recurrent disease translates into substantial morbidity. From a public health standpoint, the high prevalence of HSV-2 among this group of sexually active people has implications for HIV transmission, as HSV-2 has been shown to reactivate more frequently among immunocompromised individuals, potentially rendering them contagious for both infections.

This study demonstrates that HSV-2 testing among HIV seropositive participants is acceptable, and not associated with negative psychosocial consequences. As concern for the psychosocial impact of HSV serological testing has been cited as the major deterrent from the routine introduction of such tests into clinical care, ${ }^{31}$ this study should be reassuring, suggesting that those with HIV infection will adequately cope with the knowledge of having HSV-2 infection.

\section{ACKNOWLEDGEMENTS}

This study was supported in part by CDC Prevention Research Initiative UR6/CCU017828-02 and NIH grants AI-30731 and AI27757.

The authors of this paper wish to express sincere appreciation to Tamarind Keating and Alba Phippard for their help with data collection, Carol Glenn for invaluable assistance with recruitment, Kay Stone and Jami Leichliter for their advice, and the staff and patients of Madison Clinic for their participation.

\section{CONTRIBUTORS}

JLM, data collection, data analysis, and manuscript preparation; RAC, acquisition of the study funds, selection of the assessment instruments and design the final questionnaire, and manuscript preparation; WLHW, acquisition of study funds, study design, data analysis, and manuscript preparation; DC, data management, manuscript preparation; RA-M, study design, supervision of HSV serological testing, and manuscript preparation; AM, statistical analysis, manuscript preparation; $\mathrm{RDH}$, data collection, study implementation, manuscript preparation; RDC, acquisition of study funds, selection of the assessment instruments and design of the final questionnaire, data analysis and manuscript preparation; AW, acquisition of study funds, study design, design, selection, and assessment of study instruments, data analysis, and manuscript preparation.

The corresponding author has the right to grant on behalf of all authors and does grant on behalf of all authors, an exclusive licence (or non exclusive for government employees) on a worldwide basis to the BMJ Publishing Group Ltd to permit this article to be published in STI and any other BMJ PGL products and sublicences such use and exploit all subsidiary rights, as set out in our licence (http:// sti.bmjjournals.com/misc/ifora/licenceform.shtml).

\section{Authors' affiliations}

J L Meyer, A Wald, University of Washington, Department of Epidemiology, USA

R A Crosby, University of Kentucky, College of Public Health, Department of Health Behavior, USA

W L H Whittington, R D Harrington, A Wald, University of Washington, Department of Medicine, USA

D Carrell, R Ashley-Morrow, A S Meier, A Wald, University of Washington, Department of Laboratory Medicine, USA

R DiClemente, Emory University, School of Public Health, USA

D Carrell, Group Health Cooperative, Seattle, WA, USA

Competing interests: none declared. 


\section{REFERENCES}

1 Stamm WE, Handsfield HH, Rompalo AM, et al. Association between genital ulcer disease and acquisition of HIV infection in homosexual men. JAMA 1988;260:1429-33

2 Wald A, Link K. Risk of Human immunodeficiency virus (HIV) infection in herpes simplex virus type-2 (HSV-2) seropositive persons: a meta-analysis. $J$ Infect Dis 2002;185:45-52.

3 Russell DB, Tabrizi SN, Russell JM, et al. Seroprevalence of herpes simplex virus types 1 and 2 in HIV-infected and uninfected homosexual men in a primary care setting. J Clin Virol 2001;22:305-13

4 Corey L, Handsfield HH. Genital herpes and public health: addressing a global problem. JAMA 2000;283:791-4.

5 Corey $\mathrm{L}, \mathrm{Wald} \mathrm{A}, \mathrm{Celum} \mathrm{CL}$, et al. The effects of herpes simplex virus-2 on HIV-1 acquisition and transmission: a review of two overlapping epidemics. $J$ Acquir Immune Defic Syndr 2004;35:435-45.

6 Schacker T, Zeh J, Hu H, et al. Changes in plasma human immunodeficiency virus type 1 RNA associated with herpes simplex virus reactivation and suppression. J Infect Dis 2002;186:1718-25.

7 Fleming D, McQuillan G, Johnson R, et al. Herpes simplex virus type 2 in the United States, 1976 to 1994. N Engl J Med 1997;337:1105-11.

8 Mertz GJ, Schmidt O, Jourden JL, et al. Frequency of acquisition of firstepisode genital infection with herpes simplex virus from symptomatic and asymptomatic source contacts. Sex Transm Dis 1985;12:33-9.

9 Wald A, Ashley-Morrow R. Serological testing for herpes simplex virus (HSV) 1 and HSV-2 infection. Clin Infect Dis 2002;35(Suppl 2):S173-82.

10 Corey L, Wald A, Patel R, et al. Once-daily valacyclovir to reduce the risk of transmission of genital herpes. N Engl J Med 2004;350:11-20.

11 Wald A, Langenberg A, Link K, et al. Effect of condoms on reducing the transmission of herpes simplex virus type 2 from men to women. JAMA 2001;285:3100-6.

12 Swanson J, Chenitz W. Psychosocial aspects of tenital herpes: a review of the literature. Pub Health Nurs 1990;7:96-104.

13 Carney O, Ross E, Bunker C, et al. A prospective study of the psychological impact on patients with a first episode of genital herpes. Genitourin Med 1994;70:40-5.

14 Catotti DN, Clarke P, Catoe KE. Herpes revisited: still a cause of concern. Sex Transm Dis 1993;20:77-80.

15 Smith A, Denham I, Keogh L, et al. Psychosocial impact of type-specific herpes simplex serological testing on asymptomatic sexual health clinic attendees. Int J STD AIDS 2000;11:15-20.

16 Wilkinson D, Barton S, Chard S, et al. The psychological consequences in patient undergoing a POCKit HSV-2 test. Int J STD AIDS 2000;1 1:551-2.
17 Melville J, Sniffen S, Crosby R, et al. Psychosocial impact of serological diagnosis of herpes simplex virus type 2: a qualitative assessment. Sex Transm Infect 2003;79:280-5

18 Curran SL, Andrykowski MA, Studts JL. Short form of the Profile of Moods (POMS-SF): psychometric information. Psychol Assess 1995:7:8-83.

19 McNair DM, Lorr M, Droppelman LF. Manual for the profile of mood states. San Diego: Educational and Industrial Testing Service, 1971

20 Wild D, Patrick D, Johnson E, et al. Measuring health-related quality of life in persons with genital herpes. Qual Life Res 1995:4:532-9.

21 Snell WE, Fisher TC, Walters AS. The multidimensional sexuality questionnaire: an objective self-report measure of psychological tendencies associated with human sexuality. Ann of Sex Res 1993;6:27-55.

22 Folkman S, Lazarus RS. The ways of coping questionnaire. Palo Alto: Consulting Psychologists Press, 1988.

23 Strecher VJ, Rosenstock IM. The health belief model. San Francisco: JosseyBass Publishers, 1997.

24 Fisher J, Fisher W. Theoretical approaches to individual-level change in HIVrisk. In: Prochaska J, DiClemente R, eds. Handbook of HIV prevention. New York: Plenum Press, 2000:3-56.

25 Montano D, Kasprzyk D, Taplin S. The theory of reasoned action and the theory of planned behavior. In: Glanz K, Lewis F, Rimer B, eds. Health behavior and health education: theory, research and action. 2nd ed. San Francisco: Jossey-Bass Publishers, 1997:85-112.

26 Prochaska J, DiClemente R. The transtheoretical approach. In: Norcross J, Goldfried M, eds. Handbook of psychotherapy intergration. New York: Basic Books, 1992.

27 Wenzel L, Glanz K, Lerman C. Stress, coping, and health behavior. In: Glanz K, Rimer B, Lewis F, eds. Health behavior and health education: theory, research and practice. San Francisco: Jossey Bass Wiley, 2002:210-39.

28 Ashley RL, Militoni J, Lee F, et al. Comparison of western blot (Immunoblot) and glycoprotein $\mathrm{G}$-specific immunodot enzyme assay for detecting antibodies to herpes simplex virus types 1 and 2 in human sera. J Clin Microbiol 1988;26:662-7.

29 Patel R, Tyring S, Strand A, et al. Impact of suppressive antiviral therapy on the health-related quality of life of patients with recurrent genital herpes infection. Sex Transm Infect 1999:75:398-402.

30 Miyai T, Turner KR, Kent CK, et al. The psychosocial impact of testing individuals with no history of genital herpes for herpes simplex virus type 2 Sex Transm Dis 2004;31:517-21.

31 Mindel A, Taylor J. Debate: the argument against. Should every STD clinic patient be considered for type-specific serological screening for HSV? Herpes 2002;9:35-7.

\section{Call for papers}

11 th European Forum on Quality Improvement in Health Care 26-28 April 2006, Prague, Czech Republic

Deadline 30 September 2005.

For further information and to submit online go to: www.quality.bmipg.com 